\title{
MENUMBUHKAN WAWASAN EDUPRENEUR MAHASISWA MELALUI PROGRAM KKN PPM
}

\author{
Iin Purnamasari \\ PGSD, Fakultas Ilmu Pendidikan \\ Universitas PGRI Semarang \\ E-mail: iinpurnamasari@upris.ac.id
}

\begin{abstract}
ABSTRAK
Fokus program kegiatan adalah peningkatan penghasilan anggota Keluarga Mitra melalui program unggulan budi daya udang vannamei di tambak. Pembentukan kluster program yang meliputi: (1) kluster produksi dan pengembangan budi daya udang vannamei, (2) kluster pemasaran hasil, 3) kluster sosial, humaniora dan kesehatan masyarakat. Kluster yang terdiri atas dosen, mahasiswa, pemerintah kabupaten, dan masyarakat/mitra kerja ini bekerja secara sinergis dan terpadu untuk menghasilkan target/luaran/output yang telah ditentukan. Penjaminan berkelanjutan (sustainability) program dilakukan melalui pengembangan kerjasama (networking) dengan berbagai elemen masyarakat, akademisi, stake holder, serta industri. Pelaksanaan program KKN PPM berwawasan edupreneur mendapatkan penilaian dari mahasiswa selaku pelaksana kegiatan dalam kategori baik dan sangat baik. Mitra memberikan penilaian sangat baik dalam aspek pelaksanaan kegiatan.
\end{abstract}

Kata Kunci: Edupreneur, KKN PPM

\section{LATAR BELAKANG}

Edupreneurship merupakan bagian dari entrepreneurship yang unik di bidang pendidikan. Entrepreneurship adalah usaha kreatif atau inovatif dengan melihat atau menciptakan peluang dan merealisasikannya menjadi sesuatu yang memiliki nilai tambah (ekonomi, sosial, dll). Entrepreneurship di bidang sosial disebut sosiopreneurship, di bidang edukasi disebut edupreneurship, di internal perusahaan disebut interpreneurship, di bidang bisnis teknologi disebut teknopreneurship (Alim, 2009). Sementara itu, Oxford Project (2012) menjelaskan edupreneurship adalah sekolah-sekolah/lembaga pendidikan yang selalu melakukan inovasi yang bermakna secara sistemik, perubahan transformasional, tanpa memperhatikan sumber daya yang ada, kapasitas saat ini atau tekanan nasional dalam rangka menciptakan kesempatan pendidikan baru dan keunggulan. Bagi Agrawal (2013), dua pengertian tersebut mengandung makna yang berbeda. Dalam pengertian pertama, edupreneurship lebih banyak berorientasi pada profit yang banyak memberi keuntungan finansial. Definisi kedua lebih umum yaitu semua usaha kreatif dan inovatif sekolah/lembaga pendidikan yang berorientasi pada keunggulan.

Pada program KKN PPM yang menjadi salah satu skema pengabdian keppada masyarakat Kementerian Riset Teknologi dan Pendidikan Tinggi/Kemenristekdikti melibatkan kelompok mahasiswadari berbagai fakultas dan program studi. Setiap mahasiswa melakukan pekerjaan sejumlah Jam Kerja Efektif Mahasiswa/JKEM selama minimal 1 bulan. Orientasi program didasarkan pada hasil analisis situasi yang telah dilakukan melalui studi pendahuluan pada tahap sebelumnya. Program-program yang dilaksanakan berbasis masalah dan 
potensi wilayah yang telah dilaksanakan di Desa Mororejo Kecamatan Kaliwungu Kabupaten Kendal Propinsi Jawa Tengah.

Penduduk Desa Mororejo Kecamatan Kaliwungu Kabupaten Kendal sebagian besar bermata pencaharian sebagai petani, buruh tani, petani tambak, nelayan maupun buruh pabrik. Buruh tani banyak memiliki waktu luang karena pekerjaan yang tersedia bersifat musiman, sehingga di luar musim mereka menjadi penganggur. Beberapa orang berkelompok memelihara udang vannamei dengan sistem tambak baik secara tradisional maupun intensif. Usaha yang dirintis warga tidak dapat berjalan dengan baik, bahkan tidak jarang yang harus merugi. Biaya yang diperlukan untuk budi daya udang vannamei dengan sistem intensif cukup besar. Ketidakberhasilan budi daya udang vannamei tersebut diakibatkan banyak hal, terutama (a) penggantian air kolam yang tidak dapat dilaksanakan secara rutin, (b) pengetahuan tentang budi daya udang vannamei sangat terbatas, (c) tingkat kematian benih tinggi, dan faktor lain yang terjadi akibat fenomena alam.

Berangkat dari kondisi di atas, Tim KKN PPM Universitas PGRI Semarang membentuk beberapa vokasi yang dipersiapkan di DesaMororejo, yaitu (a) vokasi berbasis perikanan budi daya udang vannamei, (b) vokasi berbasis industry rumah tangga. Kedua vokasi tersebut dilaksanakan dengan sasaran yang berbeda. Vokasi berbasis industry rumah tangga dipersiapkan untuk sasaran ibu-ibu yang senang berjualan, dan vokasi yang berbasis perikanan budi daya udang vannamei dipersiapkan untuk semua penduduk. Vokasi/keterampilan unggulan yang dipilih berdasarkan diskusi antara Kelompok Mitra, tokoh masyarakat, LPPM Universitas PGRI Semarang, Badan Pemberdayaan Masyarakat dan Desa Kabupaten Kendal, Badan Perencanaan Pembangunan Daerah Kabupaten Kendal, dan masyarakat Desa Mororejo adalah budi daya udang vannamei.

Usulan program secara garis besar dan sistematis untuk dapat menyelesaikan masalah serta cara pemberdayaan masyarakat agar kegiatan dapat berlangsung berlelanjutan dapat antara lain: pembentukan kluster program yang meliputi: (a) kluster produksi dan pengembangan budi daya udang vannamei, (b) kluster pemasaran hasil, (c) kluster sosial, humaniora dan kesehatan masyarakat. Kluster yang terdiri atas dosen, mahasiswa, pemerintah kabupaten, dan masyarakat/mitra kerja ini bekerja secara sinergis dan terpadu untuk menghasilkan target/luaran/output yang telah ditentukan. Selanjutnya diberlakukan adanya penjaminan berkelanjutan program dilakukan melalui pengembangan kerjasama (networking) dengan berbagai elemen masyarakat, akademisi, stakeholder, serta industri. Pelaksanaan program didasarkan pada riset yang telah dilakukan oleh dosen, instansi terkait, dan mahasiswa TIM KKN-PPM Universitas PGRI Semarang yang terdiri dari berbagai disiplin ilmu yang diharapkan dapat memadukan aspek multi disipliner untuk diterapkan dalam masyarakat yang terkait dengan wawasan wirausaha melalui bidang pendidikan atau yang dikenal sebagai edupreneur. 


\section{METODE PELAKSANAAN}

Pelaksanaan program secara garis besar dan sistematis untuk dapat menyelesaikan masalah serta cara pemberdayaan masyarakat agar kegiatan dapat berlangsung berkelanjutan dapat dijabarkan dalam skema sebagai berikut:

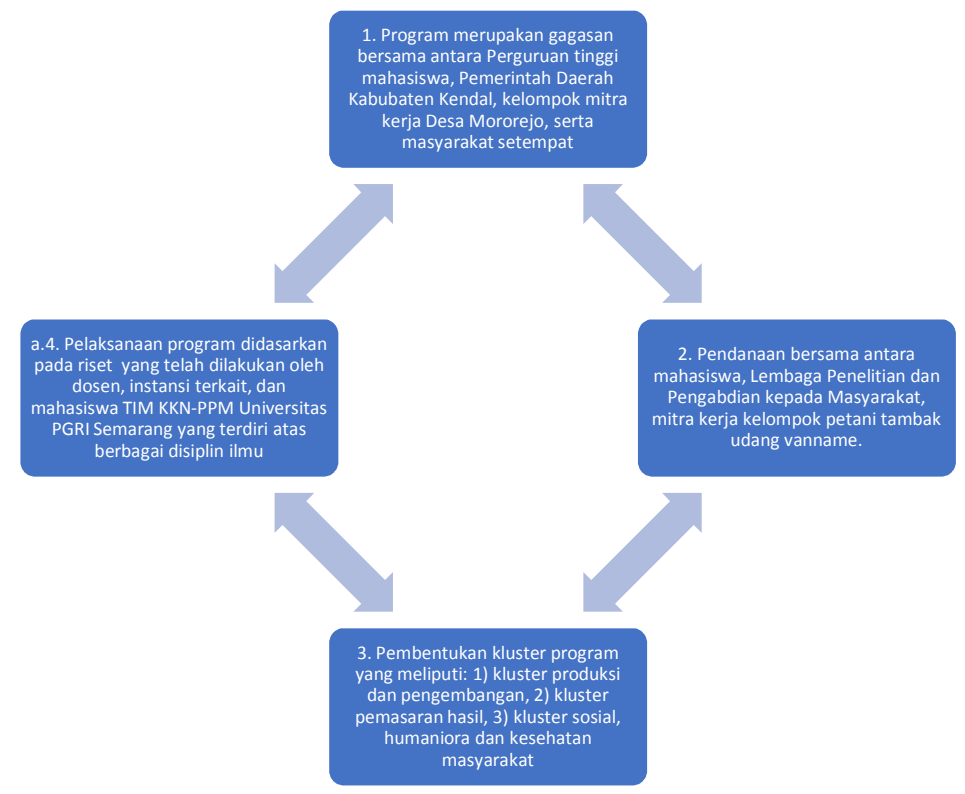

Gambar 1. Metode Penyelesaian

Metode yang digunakan untuk mengatasi permasalahan adalah dengan melakukan pendekatan strategis yang dilakukan dalam beberapa tahap, sebagaimana tersaji dalam bagan berikut:

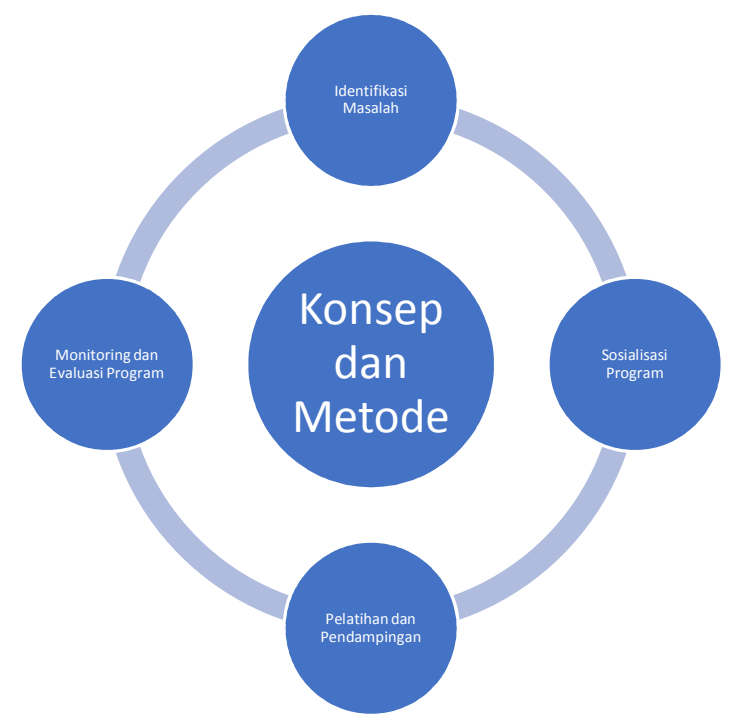

Gambar 2. Konsep dan Metode Pelaksanaan Program KKN PPM 
Pelaksanaan Program KKN PPM dilaksanakanselama 1,5 bulan dari bulan Agustus sampai dengan September 2017, oleh 3 orang dosen Universitas PGRI Semarang yang bertindak selaku 1 ketua dan 2 anggota sekaligus Dosen Pembimbing Lapangan/DPL, sertamelibatkan 40 orang mahasiswa sebagai peserta KKN dari berbagai fakultas yang ada. Masing-masing dosen memilikikompetensi yang berbeda-beda yaitu: bidang kebijakan publik, dan pendidikan.

Tahap awal dilakukan survei lapangan pada kelompok petani tambak udang vannamei, yang secara khusus melakukan wawancarayang melibatkan 2 kelompok yaitu Sekar Makmur dan Jaya Makmur, dan juga melakukan pengamatanpada proses budidaya dan penjualan. Dari hasil diskusi dengan anggotakelompok Mitra, diperoleh kesepakatan menentukan3 prioritas permaslahan mitra yaitu: permasalahanproduksi, permasalahan pengembangan aneka olahan udang vannamei, dan yangterakhir adalah permasalahan pemasaran. Selanjutnya, melalui program KKN PPM yangdidanai oleh KemenristekDikti diprogramkan budidaya udang vannamei secara intensif dan pengembangan aneka olahan.

\section{HASIL DAN PEMBAHASAN}

Hasil yang diwujudkan sesuai dengan tema KKN-PPM adalah; (a) memberikan alternative penyelesaian masalah yang nyata bagi pemberdayaan masyarakat Desa Mororejo dengan meningkatkan penghasilan mereka. Bagi pemilik UKM penghasilan bertambah dan anggota binaan penghasilannya meningkat dari tidak memiliki penghasilan tambahan menjadi mempunyai penghasilan, (b) meningkatkan lapangan kerja bagi buruh tani dan penganggur di Desa Mororejo, (c) meningkatkan kemitraan yang sinergis antara Perguruan Tinggi, pemerintah Kabupaten Kendal dan masyarakat Jawa Tengah secara umum.Hasil program KKN PPM tersebut menunjukkan keberhasilan mahasiswa dalam meningkatkan wawasan edupreneur yang dimilikinya, sebagaimana diuraikan dalam tabel berikut:

Tabel 1. Penilaian Mahasiswa atas Program KKN PPM Berwawasan Edupreneur

\begin{tabular}{|c|l|c|}
\hline No. & \multicolumn{1}{|c|}{ Aspek } & $\begin{array}{c}\text { Hasil Penilaian } \\
\text { Rata-Rata (\%) }\end{array}$ \\
\hline 1. & $\begin{array}{l}\text { KKN PPM menjadi alternatif Pemberdayaan } \\
\text { Masyarakat untuk meningkatkan Penghasilan } \\
\text { Warga }\end{array}$ & 87,5 \\
\hline 2. & $\begin{array}{l}\text { KKN PPM meningkatkan Lapangan Kerja bagi } \\
\text { Buruh Tani dan Penganggur }\end{array}$ & 75 \\
\hline 3. & $\begin{array}{l}\text { KKN PPM menjadi sarana meningkatkan } \\
\text { kemitraan yang sinergis antara Perguruan } \\
\text { Tinggi, pemerintah dan masyarakat }\end{array}$ & 82,5 \\
\hline 4. & $\begin{array}{l}\text { Berorientasi meningkatkan profit yang banyak } \\
\text { memberi keuntungan finansial }\end{array}$ & 85 \\
\hline 5. & $\begin{array}{l}\text { Mendorong usaha kreatif dan inovatif lembaga } \\
\text { pendidikan yang berorientasi pada keunggulan. }\end{array}$ & \\
\hline
\end{tabular}

Sumber: Pengolahan Data, 2017

Berdasarkan tabel 1 dapat diketahui bahwa penilaian mahasiswa terhadap pelaksanaan KKN PPM berwawasan edupreneur dalam aspek alternatif Pemberdayaan Masyarakat untuk meningkatkan penghasilan warga tergolong 
dalam level sangat baik, sementara pada aspek KKN PPM meningkatkan lapangan kerja bagi buruh tani dan penganggur pada level baik. Demikian juga pada aspek KKN PPM menjadi sarana meningkatkan kemitraan yang sinergis antara Perguruan Tinggi, pemerintah dan masyarakat, serta aspek berorientasi pada peningkatan profit yang banyak memberi keuntungan finansial. Sedangkan pada aspek mendorong usaha kreatif dan inovatif lembaga pendidikan yang berorientasi pada keunggulan mencapai kategori sangat baik.

Tabel 2.Indikator Skor Penilaian

\begin{tabular}{|c|c|}
\hline Skor Rata-Rata & Nilai \\
\hline $85-100$ & Sangat Baik \\
\hline $70-84$ & Baik \\
\hline $55-70$ & Sedang \\
\hline $40-54$ & Kurang \\
\hline$\leq 40$ & Jelek \\
\hline
\end{tabular}

Dengan demikian, program KKN mahasiswa Universitas PGRI Semarang dalam kegiatan Pembelajaran Pemberdayaan Masyarakat/PPM, dapat mencapai tujuan utama program bagi mahasiswa yaitu usaha kreatif dan inovatif mahasiswa sebagai salah satu unsur civitas akademika lembaga pendidikan yang berorientasi pada keunggulan atau potensi masyarakat, sebagaimana pandangan Agrawal (2013), mengenai salah satu karakteristik edupreneur. Adapun penilaian mitra atas pelaksanaan KKN PPM berwawasan edupreneur tersaji dalam tabel berikut:

Tabel 3. Penilaian Mitra atas Pelaksanaan KKN PPM

\begin{tabular}{|l|c|}
\multicolumn{1}{|c|}{ Aspek } & \begin{tabular}{c} 
Berwawasan Edupreneur \\
\hline \multicolumn{1}{|c|}{$(\mathbf{\%})$}
\end{tabular} \\
\hline Kesesuaian program dengan kebutuhan mitra & 90 \\
\hline Pelaksanaan program & 92 \\
\hline $\begin{array}{l}\text { Keterlibatan mahasiswa dalam kegiatan } \\
\text { budidaya }\end{array}$ & 90 \\
\hline Pengembangan aneka olahan & 85 \\
\hline
\end{tabular}

Sumber: Pengolahan Data, 2017

Berdasarkan tabel 3 dapat diketahui bahwa mitra yang berjumlah 2 kelompok yaitu Sekar Makmur dan Jaya Makmur, yang berjumlah 10 Kepala Keluarga memberikan penilaian dalam kategori sangat baik pada semua aspek dari pelaksanaan KKN PPM yaitu kesesuaian program dengan kebutuhan mitra, peaksanaan program, keterlibatan mahasiswa dalam kegiatan budidaya, dan pengembangan aneka olahan.

\section{SIMPULAN}

Berdasarkan hasil dan pembahasan diketahui bahwa program Pembelajaran Pemberdayaan Masyarakat/PPM melalui KKN mahasiswa Universitas PGRI 
Semarang menghasilkan beberapa hal yaitu (a) memberikan alternatif penyelesaian masalah yang nyata bagi pemberdayaan masyarakat Desa Mororejo dengan meningkatkan penghasilan, (b) meningkatkan lapangan kerja bagi buruh tani dan penganggur di Desa Mororejo, (c) meningkatkan kemitraan yang sinergis antara Perguruan Tinggi, pemerintah Kabupaten Kendal dan masyarakat Jawa tengah secara umum. Ketiga hal tersebut diupayakan melalui penerapan wawasan edupreneur yang menjadi modal bagi mahasiswa dalam pengembangan pemberdayaan masyarakat selanjutnya.

\section{UCAPAN TERIMA KASIH}

Terima kasih disampaikan kepada DRPM Kemenristek Dikti yang telah memberikan kesempatan untuk melaksanakan usulan program, Rektor Universitas PGRI Semarang atas ijin yang diberikan terkait pembentukan tim khusus KKN mahasiswa, LPPM Universitas PGRI Semarang, Tim Kunjungan Monitor dan Evaluasi, para Dosen Pembimbing Lapangan/DPL yang mendampingi mahasiswa peserta KKN yang solid dalam menjalankan semua program.

\section{DAFTAR PUSTAKA}

Agrawal, R. 2013. How to Identify and Select a Business Opportunity and Then Implement the Business Idea? A Case on Edupreneurship. India Journal of Business Studies Quarterly, 2013, Volume 4, Number 4

Alim, Ikhwan. 2009. Peranan ITB dalam Pengembangan Kewirausahaan. Menteri Koordinator Pengembangan Kemahasiswaan Kabinet KM ITB 2009-2010. Diperoleh dari http://ikhwanalim. wordpress.com

Oxford Project. 2012. Leading Through Edupreneurship. Copyrighted to Oxford Community Schools 